\title{
SHAPING OF LOCATION CONSCIOUS INFORMATION
}

\author{
Palson Kennedy $\cdot \mathrm{R}^{1}$ and Dr.Rajashekhara ${ }^{2}$ \\ ${ }^{1}$ Department of Information Technology, PBCE, Research Scholar CMJ University, \\ Chennai, India \\ palsonkennedyr@yahoo.co.in \\ ${ }^{2}$ Department Of Electronics \& Communication Engg Prof, Impact College of \\ Engineering and Applied Sciences ,Bangalore, Karnataka, India
}

\begin{abstract}
Nowadays mobile technology is part of daily life and behavior and the mobile ecosystems are emerging, with smart phones and tablets being the foremost growth drivers. The mobile phones are no longer just another device, we rely on their competence in work and in private. We look to our mobile phones for timely and restructured information and we rely on this being provided any time of any day at any place. Nevertheless, no matter how much you depend and adore your mobile phone the quality of the information and the user experience is directly associated with the foundations and presentation of information. In this location, our activities, interactions and preferences help shape the quality of service, content and products we use. Location-aware systems use such information about end-users as input mechanisms for producing applications based on mobile, location, social, cloud and customized content services. This represents new possibilities for haul outing aggregated user-need information and includes novel sources for situationaware applications. Accordingly, a Design Research based approach has been taken to further investigate the creation, presentation and tailoring of user-centric information. Through user evaluated experiments findings show how multi-dimensional location-aware information can be used to create adaptive solutions shaping the user experience to the users' needs. Research findings in this work; highlight possible architectures for integration of cloud computing services in diverse mobile environment in future locationaware solutions.
\end{abstract}

\section{KEYWORDS:}

Location, Conscious, Shaping, diverse mobile information

\section{INTRODUCTION}

Implementing and integrate multidimensional location conscious functionality in a solution for a mobile personal information manager.

The purpose of this is to examine the implementation and exploitation of multidimensional location consciousness in mobile devices. The use of multiple sources for conscious information has been identified in the literature review, as an important factor for creating adaptive solutions 
able to tailor information to users needs. In order to fulfill the objective several tasks are accomplished:

- Define sources for location-conscious information

- Create an application for a PIM device

-Integrate the identified location-conscious sources into the application

- Perform user evaluation to explore solution feasibility

\section{LITERATURE REVIEW}

Dey (2) broadened the field of location-consciousness by his definition of the term location, building on the earlier definitions, stating that: "Location any information

that can be used to characterize the situation of an entity." Dey (2) suggested that a developer conscious of the current location would more easily be able to determine the requirements and functionality of the application under development. So far, most researchers identify location on the basis of one or a few factors. This is an interesting approach, and towards the goal of generalization and general user acceptance of the solution it is an important aspect. The major player in creating the user experience is the developer, and it is fundamental that their understanding of how to exploit location-consciousness is broad, thorough and is central in the development process. Another approach of user interaction is described by Prekop and Burnett (10) in their work where they look at the cognitive elements of location. They argued for the development of location-conscious applications supporting cognitive activities. They proposed an activity-centred location process and described this on a conceptual level. What is very interesting about their approach is the activity-focused approach that also acknowledges that an activity can be surrounded by location from the environment. Although they do not propose how to solve this technically they do agree that there are difficulties in defining and extracting environment information. Another application utilizing location on a mobile phone, though not a PIM device, is exemplified by Schmidt et al. (11).

They produced an application where users through a dynamic WAP interface could see the current state of their contacts before calling them. This meant all participants had to share their current status, but would benefit by not having anyone calling them if they were unavailable or busy. This location sensitive phone book was found useful by a large majority of their test group. One issue with the application is that although it was implemented on a mobile phone, it still needed a server application to control and manage the location (the users' status). Further improvement could be to transfer the control and consciousness of the location to the user's device.

One example of an application taking location into account is the real estate search program developed at the IBM research centre(12). The users' sequential interaction history and his interests form the basis upon which the next step of search for information is built. This was implemented and tested as a desktop application. Others have looked at location-conscious implementation used in mobile applications. A rather different approach to a location-conscious mobile phone was the experiment conducted by from the Finnish telecom industry(3), who created a location sensitive system, which delivered multimedia messages to the user's mobile phone every time s/he approached special locations on a determined route. With location as 
location-conscious input the deliverable to the user consisted of text and / or image with information relevant to the current user location.

Through these revisited examples and definitions it is shown that location-consciousness is a common part of mobile application. This is also supported by findings in the literature review highlighting the importance of location as a major factor for well received applications leading to good user experiences. The observation to be made through the literature and as emphasized in the examples revisited here is the lack of multi-dimensional location-conscious applications. The majority of location-conscious examples utilize only a small portion of the available locations and there are also openings for a stronger integration into the mobile devices. Accordingly in this chapter, an experiment for three-dimensional location conscious shaping of information is presented.

\section{EXPERIMENT SCENARIO}

Person A is approaching the railway station and upon closing in on the location the system automatically verifies his position. He is placed in city zone number two, close to the railway station in the city centre. Thereafter the system communicates with Microsoft Outlook on his mobile phone and looks up what kind of activities he has scheduled. The activity has a social location meta-tag and this is extracted as well.

Based on the acquired activity information, the social location and his current location, the system computes the user-location. For Person A a match is calculated and the action taken from the system is to automatically set him in contact with the ticket reservation office at the Stadium located next to the central railway station, where he is planning to watch tonight's match with a friend.

\section{APPLICATION DESIGN}

The developed Personal Information Manager (PIM) application consists of three different main modules: social location module, location module and activity / task module. Each of the three modules represents one locationual dimension of information and provides separately valuable information. Application logic implemented in the software application deployed to the PIM device handles connectivity with the different modules and computes the user location. Based on this the application will decide whether or not to take action and what kind of action is appropriate.

When the inputs from each of the three modules are merged, this creates a unique foundation for the application to act further upon. When calculations are performed on this data the output is interpreted as the user location. One user location will represent one specific state of location of the user for a given time and a given situation. The application will on this basis present the user with tailored information. The process is depicted in Figure 4-1. 


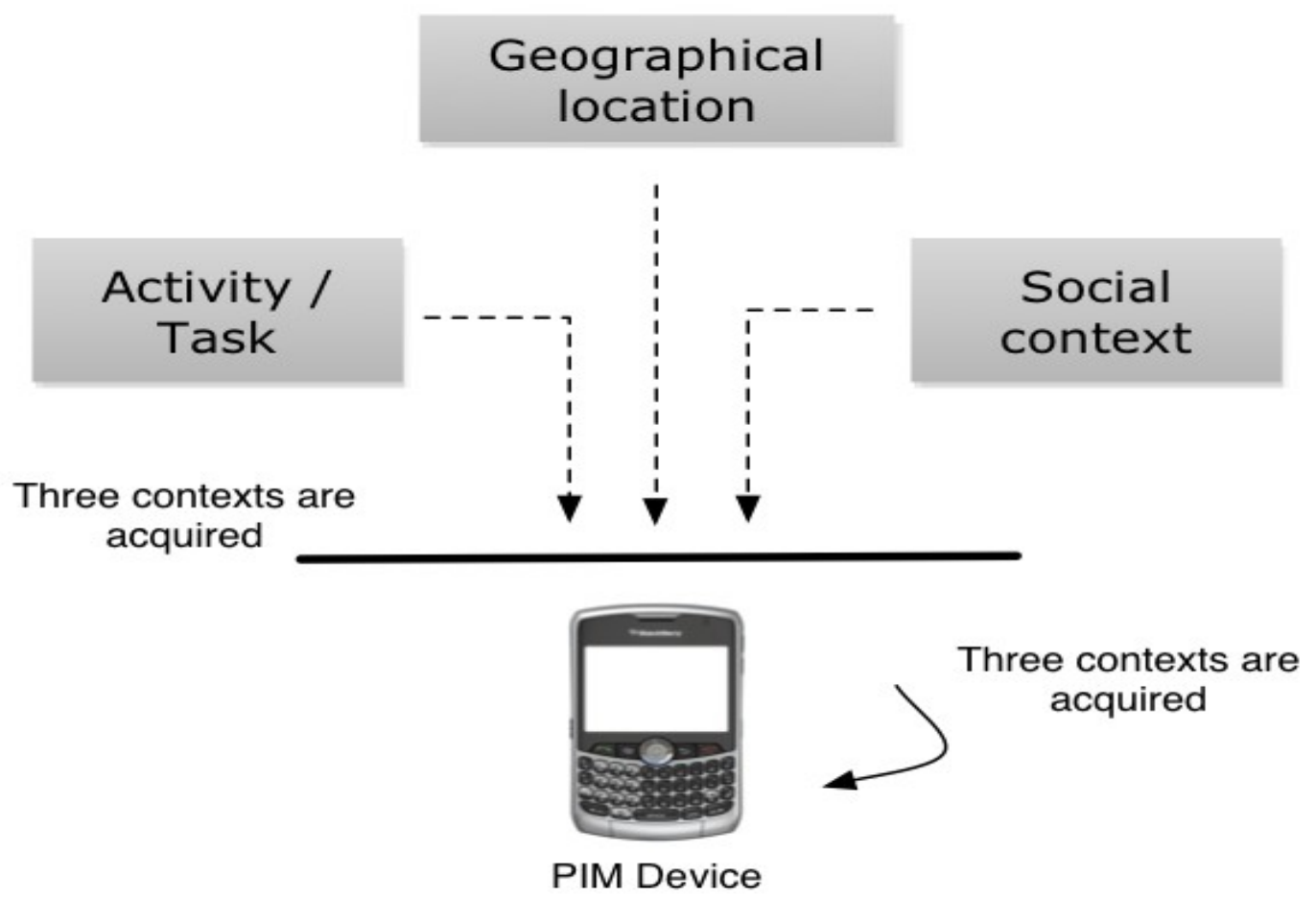

Figure 4-1: Location-conscious shaping of information from multiple dimensions

\subsection{Application Architecture}

The application was developed using Microsoft .Net C\# and implemented on a Windows Mobile 5.0 device (7). The architecture of the applications follows the guidelines of Microsoft for separation of concerns and dividing the application into different classes in different namespaces. The following figure (Figure 4-2) shows the main architectural components of the application and theirassociations. The application is built following Larmans' layer principle (8), clearly separating the architecture into individual layers with their respective responsibilities and services.

The figure shows the separation into the four main layers, with the business layer as the most important one. This is where the computation of the user location is conducted and where the main business logic is implemented. The location calculations are conducted at two separate occasions, one being when the user has moved (more than 40 meters) and the other when there is a change in activity. The result from the user-location calculation is the determining factor for whether or not this information is presented to the user. Next I will give a description of the three modules upon which location-conscious computation is based. 


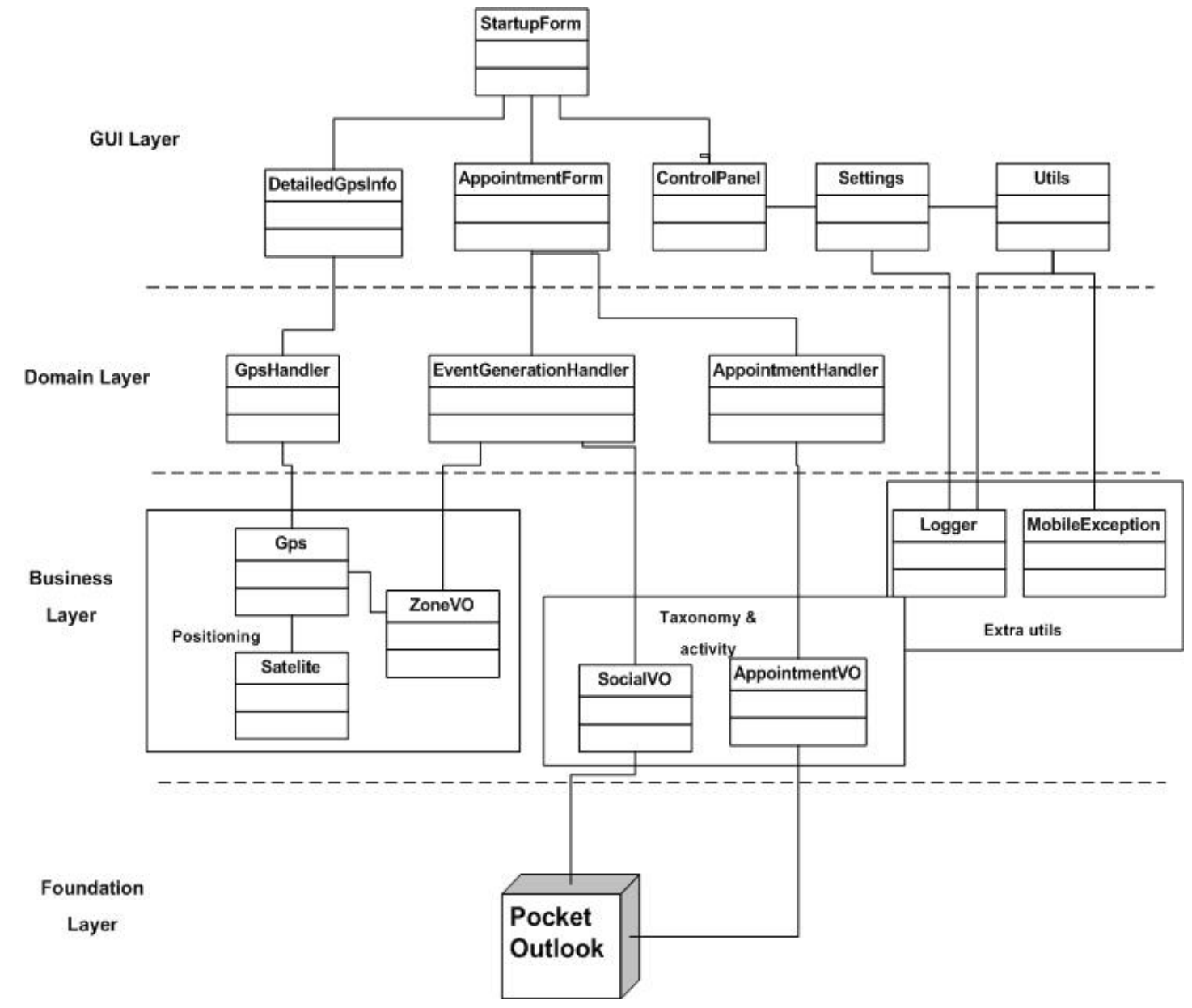

Figure 4-2: Application architecture

\subsection{Activity Module}

This module stores all user-entered activities (appointments and events) in a central storage on the device, in the Pocket Outlook database. The responsibilities for this module are to be able to communicate with this database and to be a handler of events generated in the Pocket Outlook database. Calendar communication is done through Pocket Outlook Object Model interface (POOM) (9) to achieve contact with Microsoft Pocket Outlook storage. This interface enables the possibility to retrieve and manipulate all the information in this storage. The daily maintenance and updates to this storage is done through the Windows Mobile calendar interface.

\subsubsection{Social Location Module}

This module is responsible for storing and treating the user's social location. Since the apprehension of location will be individually based, a taxonomy is applied to group the different options available. The taxonomy, available below (Table 4-1), is carefully chosen with terms and concepts interpreted in common by most people. 
International Journal of Computer Science \& Information Technology (IJCSIT) Vol 4, No 6, December 2012

\begin{tabular}{|l|l|l|l|}
\hline Categories & Leisure & Work & Travel \\
\hline \multirow{4}{*}{ Sub categories } & Cinema & Preparation & Car \\
\cline { 2 - 4 } & Shopping & Meeting & Train \\
\cline { 2 - 4 } & Food & Travelling & Foot \\
\cline { 2 - 4 } & Spare time & Own time & Tube \\
\cline { 2 - 4 } & Culture & Phone meeting & Transport \\
\hline
\end{tabular}

Table 4-1: Social Location Taxonomy

Building on the work of Prekop and Burnett (10) the social location is applied as tags to the Pocket Outlook activities and stored as meta-information together with the appointment. The user interface implementation of this is programmed into the Pocket Outlook object model as an extension to the Pocket Outlook category interface, creating a seamless experience for the user. Users can then enrich (metatag) their activities and events through a familiar interface (Figure 4$3)$.

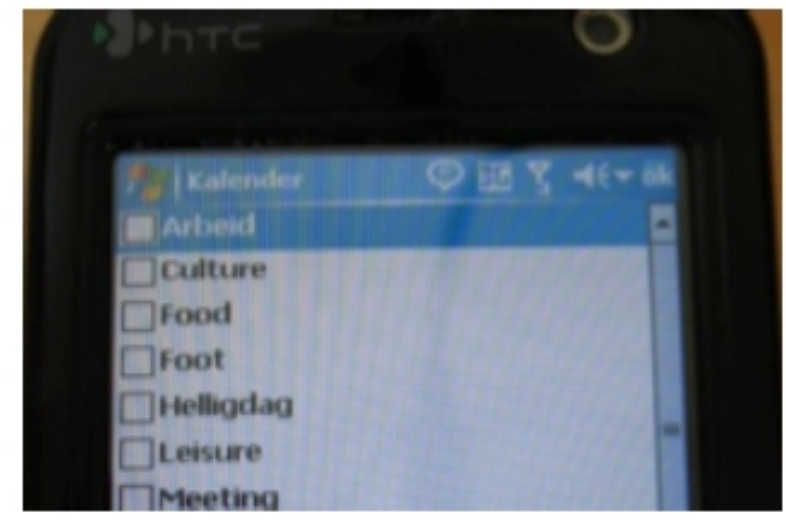

Figure 4-3: Pocket Outlook category interface

\subsection{Location Module}

The responsibility of this module is to calculate and store the most recent update of the user's geographical location. For exact positioning, an external GPS unit was used and configured through COM ports for a valid connection. Upon receiving GPS data, the string received is parsed and actual longitude and latitude coordinates are extracted. To be able to apply this information efficiently and to provide an extra layer of abstraction, the user's location was mapped to different city zones (Figure 4-4) and the user could monitor location through an admin panel 

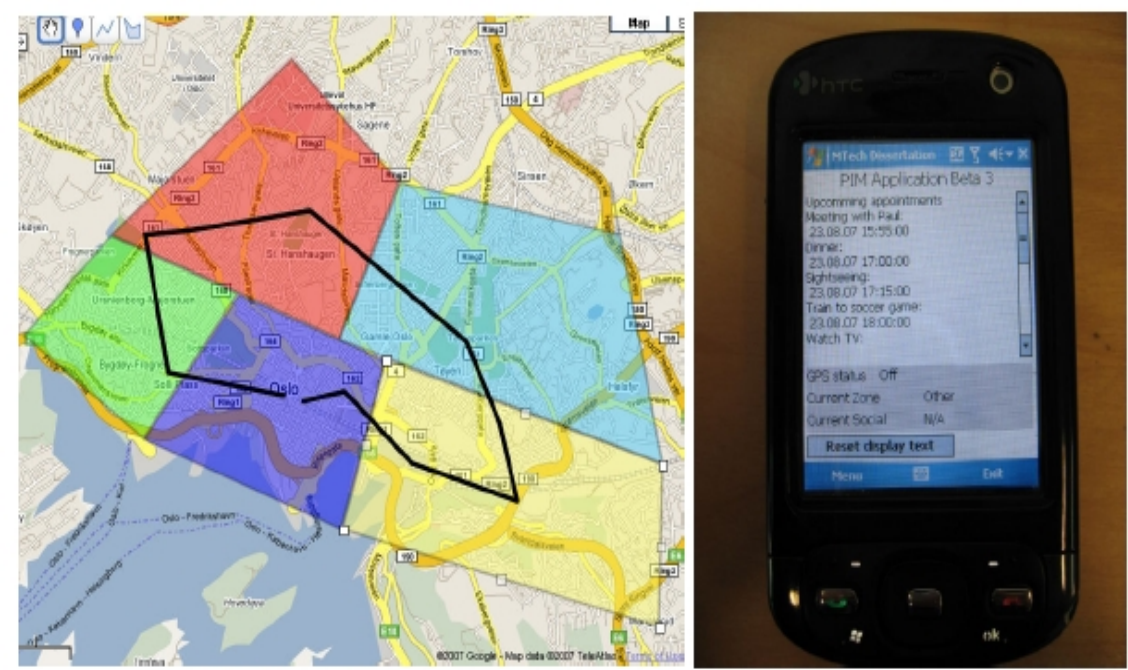

Figure 4-4 Left: City Map Right: Device admin panel with GPS logging

As the user is moving about, the actual location is updated and matched with the appropriate city zone and then stored locally. The separation into zones is based on the official city regions of chennai (9); however, in order to ease the visual presentation for the user only five out of a total of 16 zones are displayedin the map.

\subsection{Location-Conscious Computation}

The underlying computation of the user-location is the important foundation of the application. This core module of the application coordinates the presentation of information to the user. An example of rules for calculation of location-conscious information is: at system start-up, or when user position is altered with 40 meters or if a system event is triggered by change in activity. A code example for communicating with the GPS module is highlighted below:

This enables precise shaping and adjustment of information for each user and thereby a presentation of only relevant information. The sequence of calculation is described in Figure4-5. //Registration of two events

gps.DeviceStateChanged $+=$ new

GpsLib.DeviceStateChangedEventHandler(gps_DeviceStateChanged); 
International Journal of Computer Science \& Information Technology (IJCSIT) Vol 4, No 6, December 2012

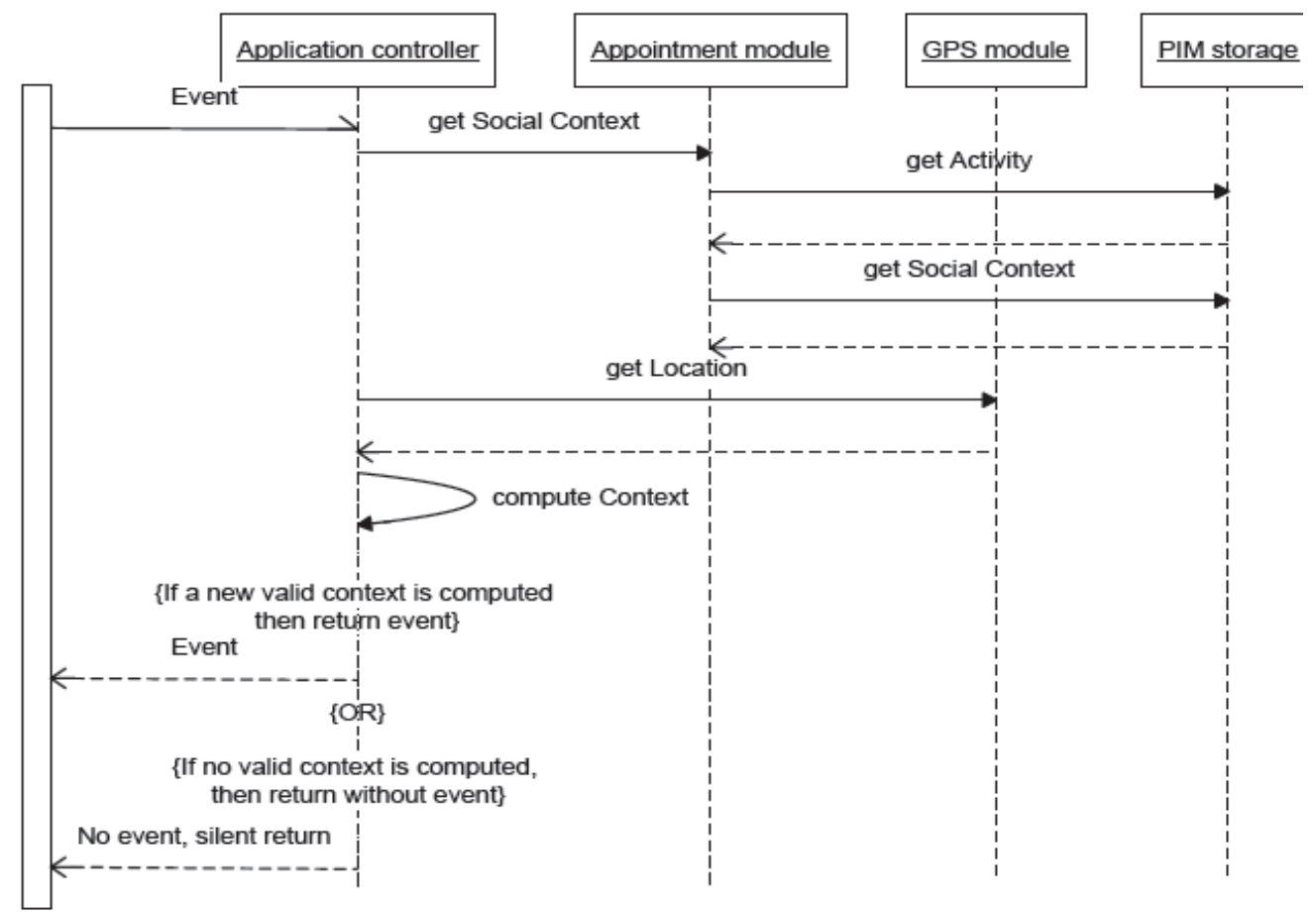

Figure 4-5: Sequence diagram of location computation

gps.LocationChanged $+=$ new

GpsLib.LocationChangedEventHandler(gps_LocationChanged);

//Calling the event update method

// update the UI on the UI thread

Invoke(updateDataHandler);

Nonetheless, there might be times when disturbance is not appropriate, for instance if one is attending a meeting, being at the library or whilst driving one's car. On such occasions one's social action (being at the library) or activity (driving a car) can be the weighting factor forcing the application to suppress an otherwise legitimate information event. The application is able to deal with this, and will present the user with missed events once his/her user-location changes to a non-intrusive mode.

Below is an example of such a possible message shown (Figure 4-6). 


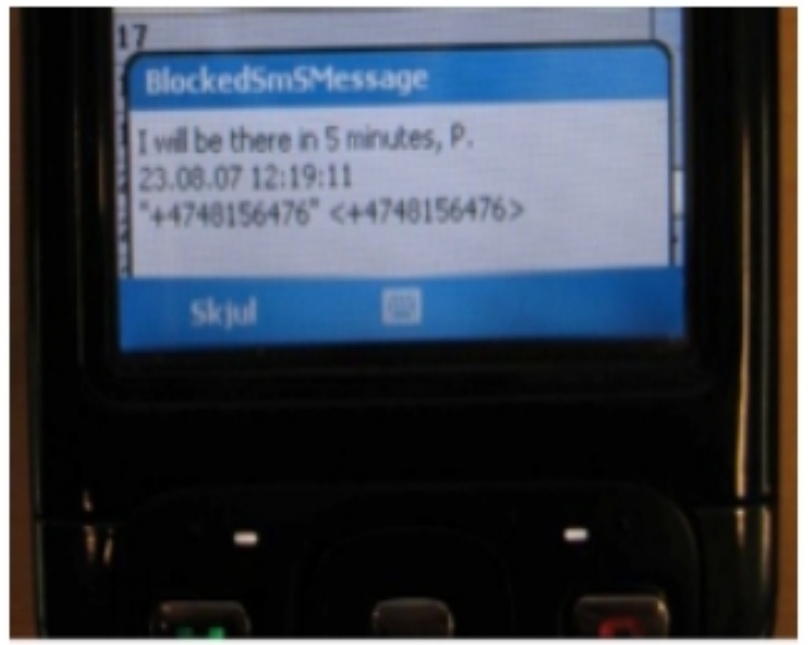

Figure 4-6: Missed event, displaying the blocked SMS

The function for determining the location-conscious setting into the user-location is, as earlier described, an important underpinning for the application. To be able to describe the actual composition of the functions, the following variables are used: a describes social setting, $\beta$ describes location and . describes current activity. The function $f$ of location can then be described as follows: Location $=\mathrm{f}(\mathrm{a}, \beta,$.$) .$

Based on this function we can then apply rules for each situation and thereby have the system act differently in each unique situation. In a given situation location can be expressed as the combination of social setting, location and activity:

Location $=f(a, B,$.

In this function, social setting a can be represented as an element from the social location taxonomy matrix, given in Table 4-1. The details of a can be given as follows:

a $\cdot[s$ i,j $\mid i=1-3, j=1-5]$

a is represented from the elements of the location activity matrix where si,j is a combination of one element from 'Categories' with an element from 'Sub categories'. For instance, s2,4 would represent travelling on work related activity. The location, given by $\beta$, is decided by the users current GPS determined position. In the details for $\beta$ given below, pi is one of the city zones (please refer to section 4.4 for city zones information).

ß. [pi $\mid \mathrm{i}=1-16]$

The users activity, ., is represented from an activity / appointment extracted from the device internal Pocket Outlook application. . is any number from 0 up to $n$ current activities (please refer to section 4.2 for details on the activity module). The details for . is expressed below:

. . [ai $\mid \mathrm{i}=0-n] \mathrm{s}$ 
To further detail and explain the implementation of the location-conscious computation, the following code samples are included. The function for determining the location conscious setting into the user-location will be run at several occasions. One major occasion is in the case the user has moved a predetermined distance, i.e. 40 meters. Given below (Figure 4-7) is an excerpt showing the initialization of the function where a GPS event is received, and the chain of command for the location-conscious computation is started.

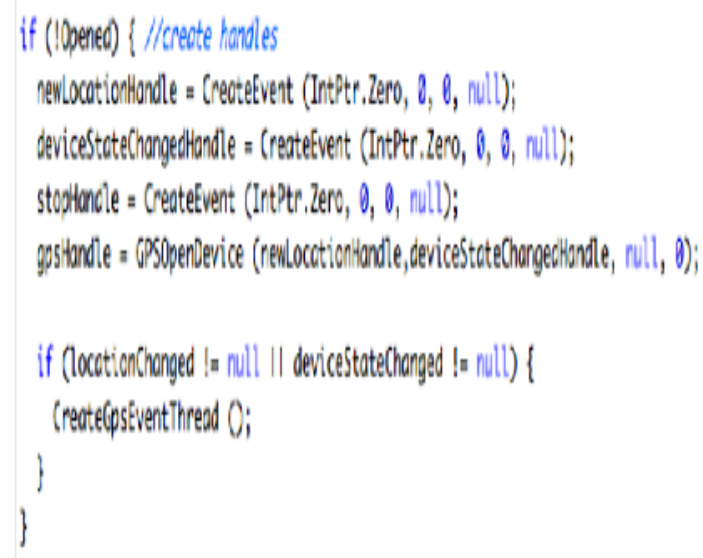

Figure 4-7: Code excerpt one from function for location-conscious computation

From the following code excerpt (Figure 4-8), a snippet from the implementation of the locationconscious computation is shown. This code snippet is focused from one part of the program where user action is decided.

For a given user, with presence in a given city zone, action can be taken on the background of the current social status and on-going activity. In this proof of concept solution, the action taken towards the user were presentation of a website matching the computed user location. 
International Journal of Computer Science \& Information Technology (IJCSIT) Vol 4, No 6, December 2012

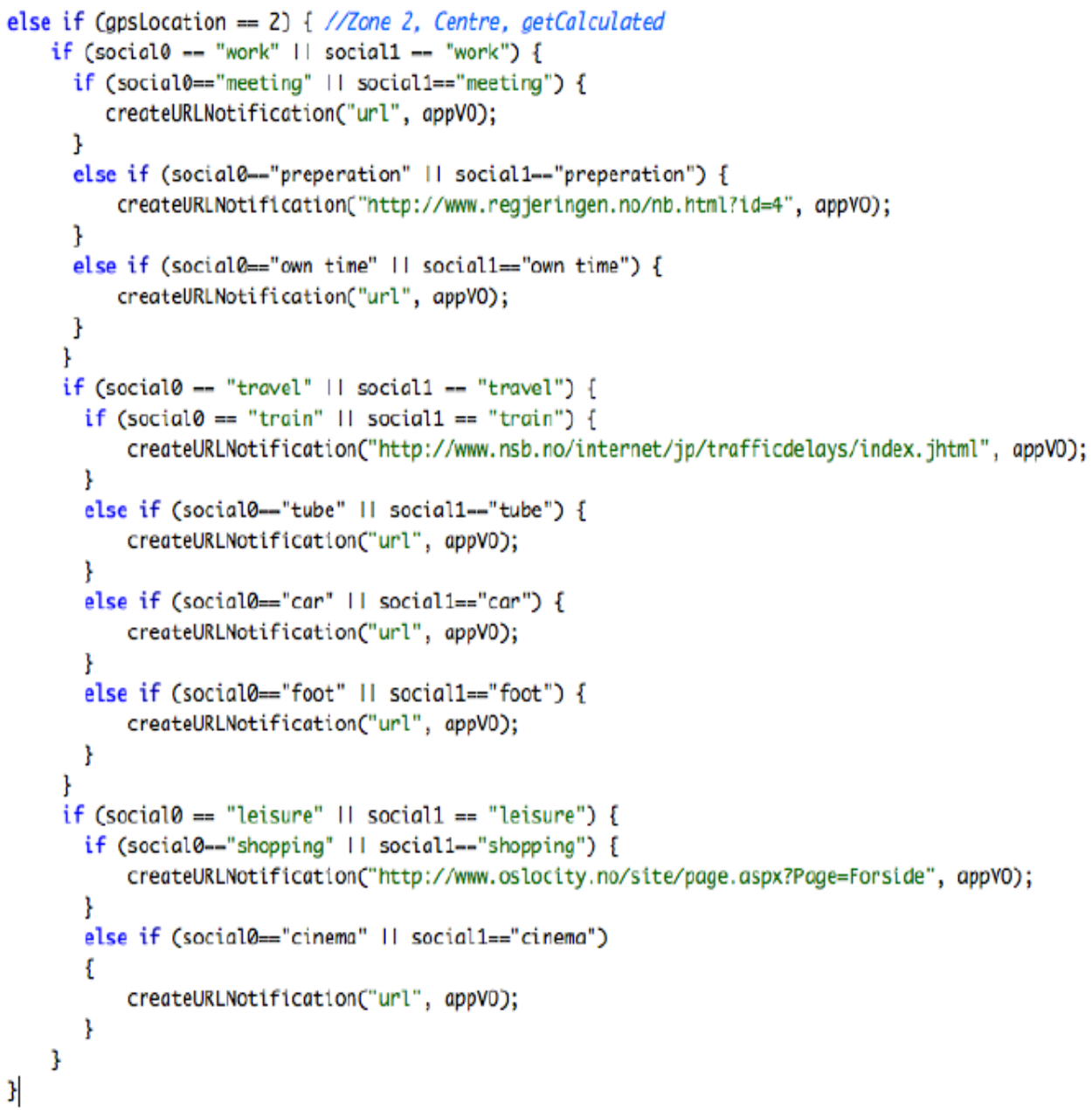

Figure 4-8: Code excerpt two from function for location-conscious computation

\subsection{Participants}

A total of 15 persons, 4 females and 11

\begin{tabular}{|l|l|l|l|}
\hline User Age group & $\begin{array}{l}\text { Rich experience } \\
\text { wih Technology }\end{array}$ & $\begin{array}{l}\text { Medium experince with } \\
\text { Technology }\end{array}$ & $\begin{array}{l}\text { Low experience with } \\
\text { Technology }\end{array}$ \\
\hline Male,age20-25 & 4 & 1 & 1 \\
\hline $\begin{array}{l}\text { Femanle, age } \\
20-25\end{array}$ & 2 & & 1 \\
\hline Male,age25-30 & 2 & 2 & \\
\hline $\begin{array}{l}\text { Femanle, age } \\
\text { 25-30 }\end{array}$ & & 1 & \\
\hline Male,age, 30-45 & & 1 & \\
\hline
\end{tabular}

Table 4-2 User breakdown in sex, age and technological expertise . 
males aged between 20 and 45, participatedin a real-world evaluation. The test persons varied in gender, age and technological experience according to the above table.

\subsection{Material}

The application is designed for and implemented on a HTC 3600 Pocket PC phone running Windows Mobile 5. This device was chosen as it, at the time, had a powerful hardware specification and a touch screen interface for manipulation. At the time of testing, the participant was given the phone device, as well as a separate sheet of instructions for how to operate it .

\subsection{Procedure}

The user testing was accomplished by having 15 persons individually use the application for approximately half a day each (around 4 hours). The test consisted of the persons using the developed prototype application on the Windows Mobile phone that was handed out to them. Whilst using the device they performed practical tasks as given in the task list. At the beginning of each test session, the candidates were given this task list (Table 4-3) and s/he had to enter all appointments into the application. This ensured all participants having the same application setup.

When performing the test, all participants moved through the city according to the scheduled events. During the evaluation, the user-location was continuously monitored and calculated, and where action appropriate accordingly to the rules were taken by the application.

\begin{tabular}{|l|l|l|l|l|}
\hline $\begin{array}{l}\text { Appointment } \\
\text { Subject }\end{array}$ & $\begin{array}{l}\text { Location / } \\
\text { Zone }\end{array}$ & Start & Categories & Comments \\
\hline $\begin{array}{l}\text { Train at } \\
\text { central station }\end{array}$ & 2 & 1.00 & Travel, train & \\
\hline $\begin{array}{l}\text { Shopping at } \\
\text { T.Nagar }\end{array}$ & 2 & $+20 \mathrm{~min}$ & Leisure shopping & Sensitive private \\
\hline $\begin{array}{l}\text { Meeting at } \\
\text { company Y seeing at }\end{array}$ & 1 & $+20 \mathrm{~min}$ & Work meeting & \\
\hline $\begin{array}{l}\text { Site } \\
\text { Guindy at Egmore }\end{array}$ & 3 & $+20 \mathrm{~min}$ & Travel foot & \\
\hline $\begin{array}{l}\text { Tour at } \\
\text { museum }\end{array}$ & 5 & $+20 \mathrm{~min}$ & Leisure & \\
\hline $\begin{array}{l}\text { Tea break at } \\
\text { Mount road }\end{array}$ & 5 & $+20 \mathrm{~min}$ & Travel & Route stop \\
\hline Travel chepauk & 3 & $+20 \mathrm{~min}$ & Work & None \\
\hline High court & 2 & $+10 \mathrm{~min}$ & Noisure & \\
\hline Central station & 2 & &
\end{tabular}

Table 4-3: Application set-up information entered by the users into the device

When position and activity would match, the application also checked the social category before taking appropriate action. If the user were in a location setting available for receiving information, the device would present information. On the contrary, if the user was in a busy mode, or otherwise not to be disturbed, the device would cache all events and incoming SMSs 
thereby leaving the user alone. Once the user returned to normal mode, a summary of missed eventswould be displayed. By the end of the evaluation, each user was given a questionnaire (please refer to Appendix A) to complete. These questions covered three different aspects of the prototype: "Initial use", "PIM in action" and "Overall statements". The results from these questionnaires are presented and evaluated in the next section.

\section{RESULTS}

This research focuses on the implementation of a location-conscious mobile application and its ability to tailor location-conscious information depending on the calculated ontext. The questionnaire designed for this experiment, which is given in full detail in Appendix A, reflects this fact and comprises statements related to the participants' experiences when using this application and receiving tailored, location-conscious information. Users' opinions are expressed on a six-point Likert scale ranging from: strongly disagree, disagree, mildly disagree, mildly agree, agree, to strongly agree. Each option was coded with number from 1 to 6 respectively, and thereafter analysed by calculating the mean and running a T-test. An extraction of the results from this evaluation is presented in the forthcoming table.

Table 5.1, and from Figure 5.2, one sees that all answers display a positive bias Statements 2 and 4 are in fact negative statements about the application, therefore the negative bias here reflects positive user statements). The questions with a pattern of statistically significant responses have been boldfaced. In question 1, 14 out of 15 participants answered that the information displayed did match their current location

\begin{tabular}{|l|l|l|l|}
\hline S.No & Statement & Mean & t-test \\
\hline 1 & $\begin{array}{l}\text { The information provided by the reminder } \\
\text { system correctly matched my current } \\
\text { location }\end{array}$ & 4.80 & 0.000 \\
\hline 2 & $\begin{array}{l}\text { The information provided when I was } \\
\text { "Sightseeing in old town" was incorrect }\end{array}$ & 2.47 & 0.310 \\
\hline 3 & $\begin{array}{l}\text { The summary of blocked events I received } \\
\text { after appointment "DNB Nor Solli plass" } \\
\text { was useful }\end{array}$ & 3.73 & 0.135 \\
\hline 4 & The system provides duplicated information & 2.73 & 0.524 \\
\hline 5 & $\begin{array}{l}\text { I liked the fact that the application is } \\
\text { integrated with Outlook }\end{array}$ & 5.47 & 0.000 \\
\hline 6 & The reminder system is useful & 5.20 & 0.000 \\
\hline 7 & I would use this application in my daily life & 3.93 & 0.005 \\
\hline
\end{tabular}

Table 5.1: Results from user evaluation

and the responses are statistically significant. This indicates a correct calculated user location. For statement number two, 11 out of 15 respondents were negative to the fact that the information being displayed in one appointment was incorrect. This indicates that 11 were shown correct information and four had incorrect or no information displayed. There is thus a strong bias towards negative answers, a few (4) positive answers and no middle values (MA / MD). This 
polarization of results however leads to the data for this statement not to be statistically significant.

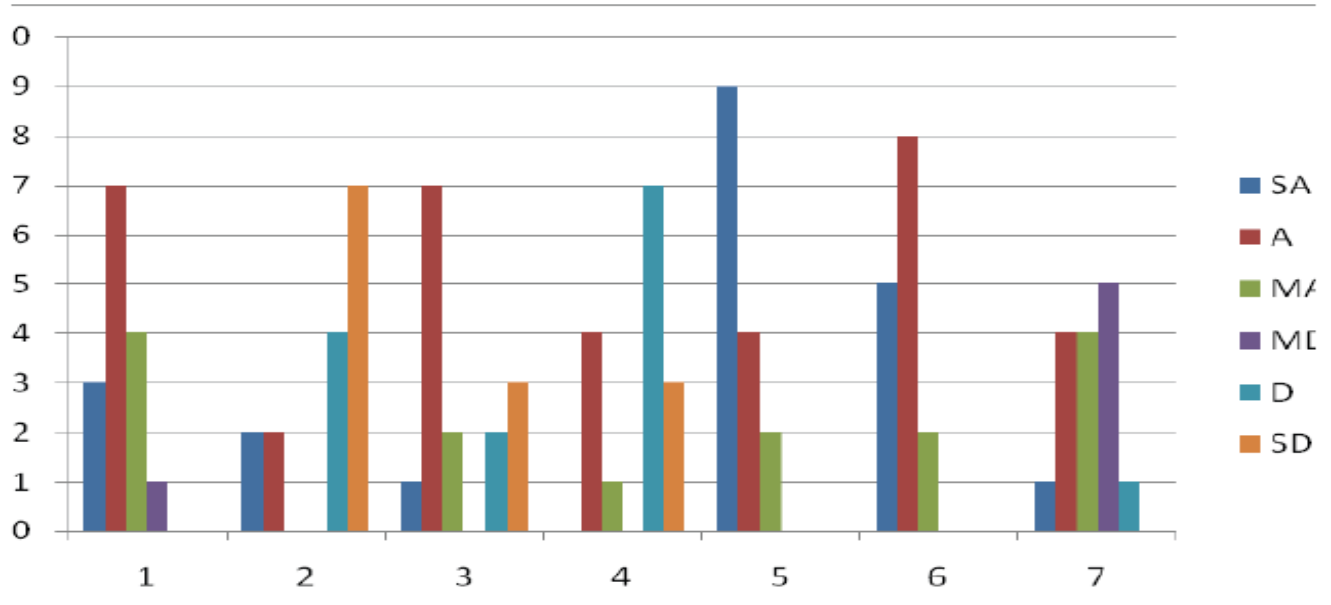

Figure 5.2: Graph displaying user evaluation results

For statement number three the majority of respondents point towards this being a useful feature, which makes this an interesting feature to pursue further. This also strongly indicates that a successful user-location computation was performed, and that system generated events received whilst in a non-disturbance mode can be successfully presented to the user when again available. The unanimous response to question five points strongly towards the appropriateness of extending a known interface, Pocket Outlook, with extra meta-tags for enriching the appointment information. In statements six and seven the user's interest in such applications for use in daily life and assessment of usefulness is further explored. The respondents indicate that although they find the application useful, it is not necessarily something they will be using daily in their lives.

\subsection{Discussion}

The application has shown the feasibility and possibilities for shaping information specific to user's needs. The location categories, given by the taxonomy, will need adaptation if such an application were to be pursued further since the application currently does not have the ability to learn from the users' actions. A possibility toadapt the taxonomy to the given domain, or for the application to learn from user action could be a feasible solution. This is in accordance with the findings of Prekop and Burnett (10) which state that it is very difficult to determine environmental information sources. Almost every source of information would need to be tailored or have a custom interface written in order to be able to deliver its services to the application. When these issues are taken care of, the user experience might improve and increase even more the positive trend in answers to question six and seven.

Moreover, information shaping is an important task to help users interpret data(12). This application focuses on shaping by having minimal information displayed at the same time, when new messages are shown, thereby easing the users' interpretation.

Currently, calendars and applications based efforts do not to a large enough extent take multi locationual information into account $(3,11$.) as they often only reproduce the information already 
available there. Thereby, this can at worst lead to incorrect display of data and at the best a reproduction of data in a new interface. This developed PIM application greatly differentiates from this by only displaying information based on the computed user location, given by the three factors social location, location and activity / task. Earlier approaches that have made use of calendar data from Pocket Outlook, often end in using Pocket Outlook data together with a simple timeline (e.g. (2)). In our approach, the use of Pocket Outlook data is extended to not only retrieve and display the data, but also to add extra meta-information to the appointments. Results from question five show that all respondents stated they liked the integration of the developed PIM application with the Outlook calendar.

In the evaluation exercise, generation of information was tightly connected with the actual task at hand and participants were asked to judge whether or not they found the application useful (question six). Results show that all 15 users involved in the evaluation thought the application gave useful value. This would indicate that the reminder system is an application with practical value for the users. As covered in the final question, the users were asked to state whether or not they would like to use this application in their daily life and one should note a separation in two camps, one positive and one negative. The positive responses highlight a possible opportunity and one should consider pursuing this in further research.

\section{CONCLUSIONS}

Location and location-consciousness have long been acknowledged as important and have generated considerable research effort. Returning to the evaluation guidelines by Hevner et al. (5), an assessment of research output from this experiment is given in the next table.

\begin{tabular}{|l|l|}
\hline $\begin{array}{l}\text { Design Research } \\
\text { Guidelines }\end{array}$ & Completion \\
\hline $\begin{array}{l}\text { Design as an } \\
\text { Artefact }\end{array}$ & $\begin{array}{l}\text { Considered complete based on the use of models to describe the architecture and } \\
\text { with the developed prototype as artefacts }\end{array}$ \\
\hline Problem Relevance & $\begin{array}{l}\text { Considered complete through the identification of the research gap after } \\
\text { reviewing existing work in literature review section and through the mapping } \\
\text { between research objective and experiment }\end{array}$ \\
\hline Design Evaluation & $\begin{array}{l}\text { Considered complete by having the artefacts (models) evaluated in practice by } \\
\text { code implementation and software testing. The final evaluation by users ensures } \\
\text { validity and provides a ground for limited generalization }\end{array}$ \\
\hline $\begin{array}{l}\text { Research } \\
\text { Contributions }\end{array}$ & $\begin{array}{l}\text { As shown through the findings and the evaluation new knowledge about } \\
\text { experiences from three-dimensional location-conscious shaping } \\
\text { extracted from this work }\end{array}$ \\
\hline Research Rigour & $\begin{array}{l}\text { Considered complete since SCRUM has been the underlying methodology for } \\
\text { the software development and software craftsmanship techniques as well as } \\
\text { eXtreme programming practices have been applied for quality assurance }\end{array}$ \\
\hline $\begin{array}{l}\text { Design as a Search } \\
\text { Process }\end{array}$ & $\begin{array}{l}\text { Considered complete because the Design Research process model by Vaishnavi } \\
\text { and Kuechler (2007) has been followed as a framework in this experiment }\end{array}$ \\
\hline $\begin{array}{l}\text { Communication of } \\
\text { Research }\end{array}$ & $\begin{array}{l}\text { Considered complete through the findings summarized in } \\
\text { this conclusion }\end{array}$ \\
\hline
\end{tabular}

Table 4-5 Research experiment mapped to evaluation guidelines 
In this the design, implementation and evaluation of an application prototype, which integrates location / location-consciousness into a PIM from a novel three-dimensional location has been presented. Social-, geographical- and activity information was the chosen dimensions for location-conscious information and integrated in a PIM allocation using Windows Mobile with the .Net framework. This realizes the objective: to mplement and integrate multidimensional location-conscious functionality in a solution for a mobile personal information manager. User evaluation of the proof of concept displayed a strong positive bias, highlighting its potential usefulness and applicability. The solution and evaluation show the viability and usefulness of such an approach and I do believe that shaping information in the manner described in this research takes the PIM concept one step further towards the ideal of providing tailored and timely information to mobile information users everywhere. For further research, exploitation of location-conscious information in different scenarios for location taxonomy adaptation would be interesting, as would implementation of more location conscious information to enhance the user experience.

\section{REFERENCES}

[1] Amazon. 2012. Amazon Elastic Compute Cloud (Amazon EC2) [Online]. Available: http://aws.amazon.com/ec2/ [Accessed March 13 2012].

[2] Dey, A., Salber, D. \& Abowd, G. 2001. A conceptual framework and a toolkit for supporting the rapid prototyping of prospective-concious applications. Human- Computer Interaction, 16, 97-166.

[3] Häkkilä, J. \& Mäntyjärvi, J. 2004. User Experiences on Combining Location Sensitive Mobile Phone Applications and Multimedia Messaging. Conference of Mobile and Ubiquitous Multimedia.

[4] Hevner, A. \& Chatterjee, S. 2010. Design Research in Information Systems: Theory and Practice, Springer.

[5] Hevner, A. R., March, S. T., Park, J. \& Ram, S. 2004. Design Science in Information Systems Research. MIS Quarterly, 28, 75-105.

[6] Larman, C. 2002. Applying UML and patterns: an introduction to object-oriented analysis and design and the unified process, Prentice Hall PTR.

[7] Microsoft. 2005. About Windows CE .NET [Online]. Available: http://msdn.microsoft.com/enus/library/ms920098.aspx [Accessed March 8 2012].

[8] Microsoft. 2012a. Pocket Outlook Object Model (POOM) API [Online]. Available: http://msdn.microsoft.com/en-us/library/ms897378.aspx [Accessed March 9 2012].

[9] Oslo Kommune. 2004. Bydelskart for Oslo [Online]. Available: http://www.oslo.kommune.no/getfile.php/oslokommune(OSLO)/Internett(OS

[10] Prekop, P. \& Burnett, M. 2003. Activities, Prospective and Ubiquitous Computing. Journal of Computer Communications, Special Issue on Ubiquitous Computing, 26, 1168-1176.

[11] Schmidt, A., Stuhr, T. \& Gellersen, H. 2001. Prospective-phonebook - Extending Mobile Phone Applications with Prospective.

[12] Zhou, M., Houck, K., Pan, S., Shaw, J., Aggarwal, V. \& Wen, Z. 2006. Enabling Location-Sensitive Information Seeking. Conference of Intelligent User Interfaces.

\section{Appendix A}

\section{Questionnaire for Experiment 1}

All participants completed this questionnaire immediately after completing the practical test with the PIM device. The questionnaire consists of three categories

with five questions in each category. All questions have six possible answers as well as an opportunity to comment on the answer. 
International Journal of Computer Science \& Information Technology (IJCSIT) Vol 4, No 6, December 2012

Evaluation after test of PIM application

In every question rate your answer according to:

Strongly Disagree | Disagree | Mildly Disagree | Mildly Agree | Agree | Strongly Agree

Initial Use:

\section{Question 1:}

It was easy to set up an appointment

SD D MD MA A SA

Comments:

\section{Question 2:}

It was difficult to find the "meeting" location category

SD D MD MA A SA

Comments:

\section{Question 3:}

It was difficult to navigate through the application

SD D MD MA A SA

Comments:

\section{Question 4:}

Finding the GPS controls and starting the GPS was easy

SD D MD MA A SA

Comments:

\section{Question 5:}

Getting a position with the GPS was difficult

SD D MD MA A SA

Comments:

PIM in action:

\section{Question 6:}

The information provided by the reminder system correctly matched my current location

SD D MD MA A SA

Comments:

\section{Question 7:}

The information provided when I was "Sightseeing in old town" was incorrect.

SD D MD MA A SA

Comments:

\section{Question 8:}

The summary of blocked events I received after appointment "DNB Nor Solli plass"was useful SD D MD MA A SA

Comments:

\section{Question 9:}

The system provides duplicated information

SD D MD MA A SA 
Comments:

Question 10:

I liked the fact that the application is integrated with Outlook

SD D MD MA A SA

Comments:

\section{Overall statements:}

\section{Question 11:}

I would have liked to receive info about alternative transportation in "train" location SD D MD MA A SA

Comments:

\section{Question 12:}

The reminder system is useful

SD D MD MA A SA

Comments:

\section{Question 13:}

The application was slow

SD D MD MA A SA

Comments:

\section{Question 14:}

The device got warm as I performed my schedule

SD D MD MA A SA

\section{Question 15:}

I would use this application in my daily life

SD D MD MA A SA

\section{Question 16:}

Do you have any overall comments or suggestions for improvements?

Comments:

Thank you for participating!

\section{Author}

Biography.

The Author is Prof \& Head of the department of Information Technology in P.B.College of Engineering,Chennai-117 who enjoys challenges of creativity and attention in detail. He is a passionate researcher in the field of information retrieval ,Data mining \& cloud computing as well. having dedicated past seven years. His professional career covered 20years in Teaching \& Industrial sector.,

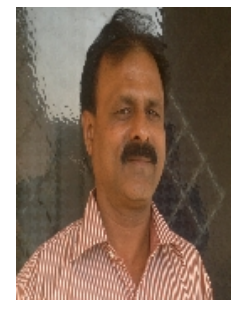

